\title{
Strategy of consolidation in gold mining as a tool for creating an effective business
}

\author{
Irina Kradenykh ${ }^{1 *}$ and Aleksei Barchukov ${ }^{2}$ \\ ${ }^{1}$ Mining Institute FEB RAS, 51 Turgenev st., Khabarovsk, 680000, Russia; \\ ${ }^{2}$ Far Eastern State University of Railway Transport, department of finance and accounting, 680000, \\ Khabarovsk, Serysheva St., 47, Russia.
}

\begin{abstract}
Annotation. The subject of the article is the search for an effective strategic solution within the framework of sustainable development of gold mining enterprises belonging to small and medium-sized mining businesses. The purpose of the study is to analyze the problem and provide a theoretical justification for the feasibility of horizontal integration for this category of gold mining enterprises. The scientific article reveals the processes of development of the gold mining industry, taking into account the state of the mineral resource base of placer gold. The role of horizontal integration and the feasibility of its application in the framework of enterprises belonging to small and medium-sized mining businesses are outlined. A method for evaluating the effectiveness of a horizontally integrated gold mining enterprise is proposed, taking into account potential synergetic effects and the possibility of production diversification. These approaches, even at the project stage, will allow us to assess the feasibility and effectiveness of the planned consolidation. Keywords: gold mining industry; placer deposits; strategic development; horizontal integration
\end{abstract}

\section{Introduction}

Modern economic growth in Russia is directly related to the level of development of the most important, strategic sectors of the national economy, including mining of precious metals. At the same time, the national economy is going through a difficult period, overcoming not only domestic problems, but also international ones caused by the tense political situation. The search for effective directions for the development of national gold mining enterprises is necessary for the formation of sustainable economic growth and improvement of the economic activity of the industry as a whole.

In placer gold mining, most companies are representatives of small and medium-sized mining businesses. Their activities are complicated by various factors, including an imbalance in the structure of gold resources, inaccessibility of deposits, increased costs for their development, insufficient development of modern technologies for mining and processing of gold-containing materials, lack of qualified personnel, etc. To get out of this situation, businesses can use internal or external growth strategies. Processes of activation of internal mechanisms lead to an increase in the profitability of assets, which allows companies to effectively develop existing skills and thereby strengthen their competitive

\footnotetext{
* Corresponding author: kradenyh_igd@mail.ru
} 
advantages. When using external growth strategies companies activate their own strengths and are able to use the opportunities provided to them more effectively [1,2]. These issues are relevant in connection with the emergence of new requirements for the methods of strategic management of gold mining enterprises in the context of crisis events and unstable development of the modern economy.

\section{Analysis of the problem of the Russian small and medium- sized businesses development in the gold mining industry}

Currently, Russia holds a leading position among countries that have preserved placer gold mining. Over the past decade, the volume of alluvial gold production has remained approximately at the same level and currently accounts for about $29 \%$ of the total production in the country. During this period, there was a constant, although small, increase in production volumes, amounting to a total of 70-72 tons of gold per year, which indicates a certain stabilization of the industry as a whole. During the past three years, the number of national gold mining enterprises has increased by $9 \%$ and currently stands at 518 companies, which indicates the investment attractiveness of the industry. At the same time, the main part of them is small enterprises with an annual production of less than 1 ton of gold per year.

Despite some positive dynamics in this production sector, there are still many unresolved problems and questions. The consequences of the financial and economic crisis and external restrictions imposed by western countries affect the functioning of Russian gold mining, through changes in the dominant adaptation strategies in small and mediumsized businesses. These consequences, first of all, cause changes in the external environment and are manifested in the form of reduced availability of financial resources necessary for normal functioning, pressure from government agencies and other factors. Therefore, in the current situation, small and medium-sized enterprises, experiencing the negative consequences of modern trends from the environment, are forced to rely solely on their own strength and internal reserves [3, 4].

Analyzing the activities of gold mining enterprises, we can draw the following conclusion: in order not just to survive, but to continue to move towards increasing the efficiency of their activities, they need to overcome the lag in technical and technological development, while achieving a high level of production and quality of processing of goldcontaining raw materials. It is obvious that the state of small and medium-sized mining enterprises requires the use of certain strategies for further development, which in turn requires improvement and adaptation of theoretical and methodological approaches to assessing their effectiveness $[5,6]$. The process of merging medium-sized and small gold mining companies is likely to become an objective inevitability in the strategic development of this segment of the industry. However, two possible scenarios for consolidation should be considered. In the first case the process of unification can be carried out according to the principle of horizontal integration by combining approximately equal to each other, enterprises. The second option can be implemented by merging a small or medium sized company with a larger gold mining enterprise [7].

\section{Theoretical aspects of integration in the Russian market}

In the theory and practice of integration associations, two main forms are most common: mergers or acquisitions (M\&A). In a merger, the result of combining approximately equal businesses is a new company; in the case of a takeover, the smaller company is integrated into the structure of a larger business $[8,9]$. In main, these strategies are aimed at increasing 
the competitiveness of enterprises and changing their scale. For example, horizontal integration combines approximately equal enterprises with homogeneous technology, vertical integration combines enterprises that are at the previous and subsequent technological stages of production, and diagonal integration consolidates multi-industry enterprises that are not technologically related.

In the case of horizontal integration, two or more businesses that are approximately equal in business volume and are engaged in the production of the same product are combined. Its main goal is to strengthen the positions of companies that are United into a single whole, and to achieve more effective and successful performance indicators on this basis by obtaining synergistic effects [10]. Businesses, using horizontal integration as a strategy, expect to strengthen their position and be able to win the best positions in this market with this product. This strategy is most appropriate if the main strategic advantages are achieved when increasing the scale of production. Integration provides the participating enterprises with stability of functioning, since larger companies with a large amount of resources can more easily cope with changes in demand for their products $[11,12]$. In wide terms, integration should be understood as the process of combining two or more economic entities with their own property on the basis of civil law relations in order to strengthen interaction and internal relations.

Analysis of the transaction market shows that the mining sector in 2015 ranks third in the rating of industries. Then there is a gradual decrease in transaction activity. Over the period from 2017 to 2018, the market for mergers and acquisitions has significantly decreased. So in 2017, 55 transactions were conducted, and in 2018 - 53 transactions. There may be several reasons for this, including sanctions, investor caution, and many other factors. According to analytical forecasts for the next 1-2 years, domestic transactions will prevail in the mining sector. At the same time, we should note the high interest in mining companies from Asian investors. If there is support from intergovernmental organizations, as well as banks, you can expect several interesting transactions over the next 1-2 years. In this regard, it is important to study the best international practices and implement the most effective solutions in Russian practice for a quick and accurate assessment of current processes and prospects.

\section{Methodological approaches to evaluating the effectiveness of horizontal consolidation}

Most foreign and domestic specialists consider the synergy effect expected as a result of complementarity or strengthening of various elements of the production system, including financial, human resources, economic and other spheres of activity as the main motive for integration. It is assumed that the total result of this interaction will far exceed the sum of the results in the case of independent operation of individual enterprises. The concept of "synergy" is of Greek origin and means assistance, cooperation, complicity. Synergy should be understood as a coordinated, mutually reinforcing action of two or more subsystems, as a result of which a single system produces a greater effect than all its subsystems separately.

The effectiveness and feasibility of the proposed consolidation of two or more gold mining companies can be judged based on the analysis and evaluation of the expected benefits of the transaction. As already mentioned, this strategy involves achieving competitive advantages due to the expected synergy and diversification of production, which is the main reason for conducting horizontal transactions. It is possible to assess the correctness of making a strategic decision on the consolidation of enterprises based on the value of such an integral indicator as the value of the company before and after the reorganization, since the value of the existing enterprise acts as an indicator of its value. 
The most well known in the world practice of assessing the value of an enterprise (business) are the cost (property), comparative (market) and income approaches. Each of them has its own methods and has an actual scope of application. However, in order to determine the future performance of an integrated enterprise, it is generally agreed that the most appropriate approach is the revenue approach, the main advantage of which is the ability to take into account the future operating conditions of the enterprise. Disadvantages include the complexity of forecasting long-term cash flows, including calculating capitalization and discount rates. Thus, the expected synergy in the field of operating activities can be determined by the formula:

$$
\mathrm{E}_{\mathrm{syn1}}=\frac{\Delta \mathrm{CF}_{\mathrm{syn} 1}}{(1+\mathrm{r})}
$$

$\Delta \mathrm{CF}_{\text {syn } 1}$ - the value of cash flows from operating activities, taking into account the impact of synergistic effects.

$$
\Delta \mathrm{CF}_{\mathrm{syn} 1}=\Delta \mathrm{S}_{\mathrm{m}}+\Delta \mathrm{S}_{\mathrm{pc}}+\Delta \mathrm{S}_{\mathrm{S}}+\Delta \mathrm{S}_{\mathrm{mc}}
$$

$\Delta \mathrm{S}_{\mathrm{m}}$ - the cost savings in the purchase of raw materials;

$\Delta \mathrm{S}_{\mathrm{pc}}-$ saving production costs;

$\Delta \mathrm{S}_{\mathrm{S}}-$ cost savings on product sales;

$\Delta \mathrm{S}_{\mathrm{mc}}$ - saving management costs.

It is proposed to calculate synergy in the financial sphere:

$$
\mathrm{E}_{\mathrm{syn} 2}=\frac{\Delta \mathrm{CF}_{\mathrm{syn} 2}}{(1+\mathrm{r})},
$$

$\Delta \mathrm{CF}_{\text {syn2 }}$ - the value of cash flows from financing activities, taking into account the impact of financial synergies:

$$
\Delta \mathrm{CF}_{\text {syn } 2}=\Delta \mathrm{S}_{\mathrm{i}}+\Delta \mathrm{S}_{\mathrm{r}}+\Delta \mathrm{S}_{\mathrm{T}},
$$

$\Delta \mathrm{S}_{\mathrm{i}}$ - savings on interest costs for raising borrowed funds;

$\Delta \mathrm{S}_{\mathrm{r}}-$ cost savings from partial replacement of borrowed capital with own capital;

$\Delta \mathrm{S}_{\mathrm{T}}-$ cost savings by reducing tax payments.

It is proposed to evaluate the synergistic effect of investment activities:

$$
\mathrm{E}_{\mathrm{syn} 3}=\frac{\Delta \mathrm{CF}_{\mathrm{syn} 3}}{(1+\Delta \mathrm{r})},
$$

$\Delta \mathrm{CF}_{\mathrm{syn} 3}$ - the value of cash flows from investment activities, taking into account the impact of investment synergies;

$\Delta \mathrm{r}$ - changing the rate of return on capital by reducing investment risks.

$$
\Delta \mathrm{CF}_{\text {syn3 }}=\Delta \mathrm{S}_{\mathrm{F}}+\Delta \mathrm{S}_{\mathrm{d}}+\Delta \mathrm{S}_{\mathrm{res}}
$$

$\Delta \mathrm{S}_{\mathrm{F}}$ - savings on investment in fixed assets through the use of trade discounts;

$\Delta \mathrm{S}_{\mathrm{d}}$ - savings on investment through shared access to $\mathrm{R} \& \mathrm{~d}$;

$\Delta S_{\text {res }}$ - savings on investment through the use of complementary resources.

The aggregate synergistic effect is proposed to be determined:

$$
\mathrm{E}_{\sum \mathrm{syn}}=\frac{\Delta \mathrm{CF}_{\mathrm{syn} 1}+\Delta \mathrm{CF}_{\mathrm{syn} 2}}{(1+\mathrm{r})}+\frac{\Delta \mathrm{CF}_{\mathrm{syn} 3}}{(1+\Delta \mathrm{r})},
$$

Cost of a horizontally integrated enterprise, taking into account the synergistic effects:

$$
\mathrm{V}_{\mathrm{p}(\mathrm{C})}=\left(\mathrm{V}_{\mathrm{p}(\mathrm{A})}+\mathrm{V}_{\mathrm{p}(\mathrm{B})}\right)-\mathrm{C}_{\mathrm{r}}+\mathrm{E}_{\sum \text { syn }},
$$

$\mathrm{V}_{\mathrm{p}(\mathrm{C})}$ - the current value of a horizontal enterprise; 
$\mathrm{V}_{\mathrm{p}(\mathrm{A})}, \mathrm{V}_{\mathrm{p}(\mathrm{B})}$ - the current value of the enterprises to integrate;

$\mathrm{C}_{\mathrm{r}}$ - the costs associated with the organization.

When determining the effectiveness of a horizontally integrated enterprise, it is proposed to use the combined synergetic effect as an efficiency criterion, the value of which should exceed the amount of costs incurred by enterprises for carrying out reorganization:

$$
\mathrm{C}_{\mathrm{r}}<\mathrm{E}_{\sum \text { syn }}
$$

The positive value of synergistic effects makes it possible to direct the released funds to strengthen the overall efficiency of the new enterprise. This may be due, for example, to the acquisition of new, more productive equipment, preparation for the development of more complex, but economically profitable natural objects, and so on. If the value of the total synergy does not exceed the amount of integration costs, then it is obvious that the new enterprise will not have cash inflows at the first stages of operation, and therefore will not be able to contribute funds to the development of activities. In this case, the ratio takes the form:

$$
\mathrm{E}_{\sum \mathrm{syn}}=\mathrm{Cr}
$$

This is the outcome of integration can be considered ineffective. If the cost of the combination exceeds the short term total synergy, this inequality means that the company is unprofitable and cash outflow:

$$
\mathrm{E}_{\text {Ssyn }}<\mathrm{Cr}
$$

obviously, this option can be considered an inefficient result of company integration.

Based on the economic indicators of two gold mining companies with an annual production volume of about $100 \mathrm{~kg}$ of gold, the cash flows of a horizontally integrated enterprise were formed and the value of synergies in various areas of activity of the consolidated company was estimated. Calculations were also made that determined the cost of horizontal integration in the amount of 0.43 million rubles. As a result, the growth coefficients of net cash flows are established, which determine the amount of synergistic effects (Fig. 1):

$$
\mathrm{k}_{\mathrm{syn}_{\mathrm{i}}}=\frac{\mathrm{Y}_{\mathrm{syn}_{\mathrm{i}}}}{\mathrm{Y}_{0}},
$$

$\mathrm{k}_{\text {syni }}$ - net cash flow growth coefficient; $\mathrm{Y}_{\text {syni }}$ - cash flow generated by taking into account the impact of synergy $\mathrm{i}$; $\mathrm{Y}_{0}$-base cash flow

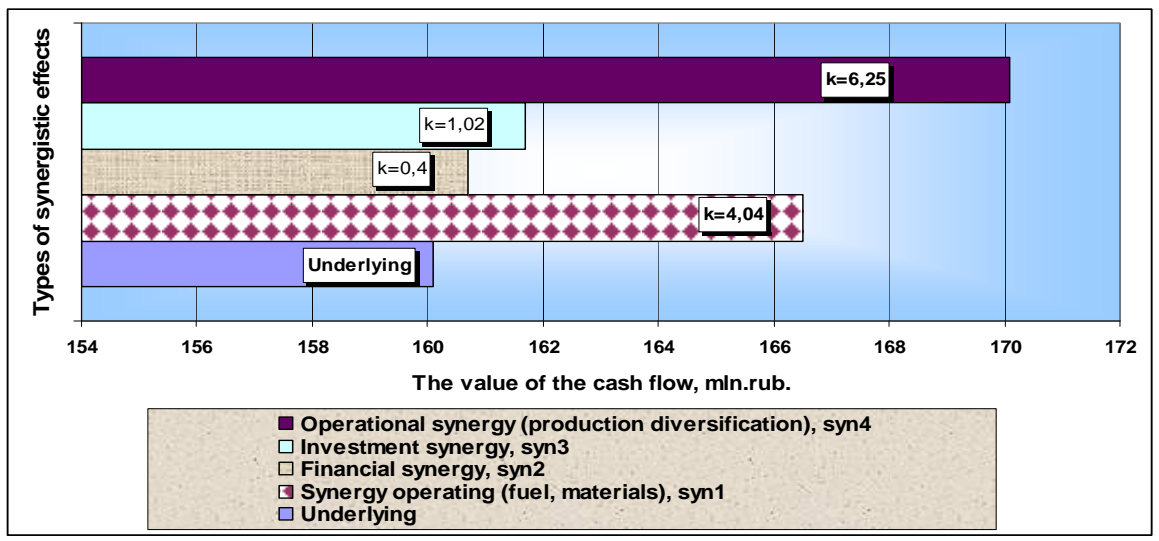

Fig. 1. The increase in cash flows as a result of the impact of synergy 
During the analysis, it was found that the value of the total average annual synergy was 1.63 million rubles, which significantly exceeded the costs incurred during the organization of the Association itself, therefore, at this stage, the decision to consolidate can be considered effective. It is obvious that the synergy effect does not arise by itself, but is the result of purposeful management. Therefore, in this case, the main issue is the possibility of achieving a synergistic effect when merging suitable companies. At the same time, it is important to determine the forms of potential synergy in advance and assess the possibility of both positive and negative effects before the transaction is concluded, which will allow you to reject ineffective options at the preparatory stage and choose more suitable candidates for the merger.

\section{Conclusion}

At the present time, in the globalized world economy, the problem of improving the efficiency of company management is particularly acute. The prospects for companies' development in the context of the economic crisis are determined by the efficiency and ability of the management apparatus to respond to rapidly changing conditions and identify new opportunities for the successful functioning of the business. One of the main tools for significantly improving management efficiency is M\&A strategies that contribute to the company's growth and increase its competitiveness. In modern economic conditions, the integration of gold mining companies will allow not only to implement more expensive projects and earn significant revenues, but also to optimize production costs, through cooperation and specialization of labor, to increase productivity and quality of work. The approaches proposed in the article will help gold mining companies to determine the direction of those strategic tasks, the solution of which will allow them to plan the achievement of targets and justify the choice of an economic development option.

\section{Reference}

1. A.V. Barchukov, I.A. Kradenykh, Management, 2(1), 18-26 (2014)

2. A.D. Chigirin, Journal of the New economic Association, 3(39), 110-126 (2018)

3. V.M. Zaerniuk, L.I. Chernikova, IU.V. Zabaikin, Financial analytics: problems and solutions, 10(9), 972-986 (2017)

4. A.E. Natalenko, V.A. Pak, A.P. Stavskii, Mineral resources of Russia. Economics and management, 1, 2-8 (2015)

5. I.A. Kradenykh, A.V. Barchukov, Improving the efficiency of gold mining based on horizontal integration (2015)

6. I.A. Kradenykh, A.V. Barchukov, Russian Journal of Management, 4(2), 108-118 (2016)

7. R. S. Foster, A. Reed Lajoux, The art of mergers and acquisitions (2004)

8. S.A. Palnichenko, K.S. Mikheeva, D.A. Kulumbetova, International journal of Humanities and natural Sciences, 10, 166-171 (2017)

9. V. Vivoda, D. Kemp, The Extractive Industries and Society, 6(1), 22-28 (2019)

10. A.E. Ivanov, E.IU. Solomatina, Economic analysis: theory and practice. 7(406), 44-56 (2015)

11. P.A. Sverchkov, Logistics and supply chain management, 3, 15 - 30 (2012)

12. J. Horsley, S. Prout, M. Tonts, S.H. Ali, The Extractive Industries and Society, 2(2), 368-380 (2015) 